\title{
RADICAL PARTICULARISM: A NATURAL LAW OF CONTEXT
}

\author{
David Jabbari, Lecturer in Law, University of Reading \\ INTRODUCTION
}

Do judges discover the law or do they create it? This is an old question, perhaps the oldest in legal thought. ${ }^{1}$ In recent years, it has been the subject of intense scrutiny in legal philosophy, particularly as it arises in the complex debate concerning the extent of law's 'objectivity'. ${ }^{2}$ For those with a realist ${ }^{3}$ disposition (that is: those who wish legal theory to be driven by practical legal questions) there is perhaps some disquiet about permitting the question to be approached exclusively in philosophical terms, with debates about the semantic conditions under which the usage of concepts is warranted replacing analysis of the specific subject matter of substantive law. A more distinctively legal approach to the question is to ask whether we should view case law as revealing a natural order which underlies and structures judicial reasoning, or whether any order we find is merely artifice and convention. The first of these views is commonly associated with natural law perspectives rooted in the doctrines of Aristotle and Aquinas (for example, corrective justice analyses ${ }^{4}$ of the law of tort which claim that there is an essential order beneath doctrines such as the non-recoverability of certain forms of economic loss, or principles of compensation). The second view is more variegated and clearly

1 It is certainly evident in Greek writings which consider law, such as in the themis/dike distinction in the Homeric poems, Aristotle's distinction between that which is naturally just (to physikon dikaion) and that which is just only by virtue of enactment (to nomikon dikaion), and in the oft-cited speech of Antigone in Sophocles' play of the same name. It is also taken up very directly in Roman times in the writings of Cicero (De legibus). For discussion of these issues see generally J.M. Kelly A Short History of Western Legal Theory, (Oxford, OUP, 1992) chaps 1 and 2.

2 See for example, N. Stavropoulos, Objectivity in Law, (Oxford, OUP, 1996), A. Marmor, "Three Concepts of Objectivity", in A. Marmor (ed), Law and Interpretation (Oxford, OUP, 1995), A. Marmor, 'An Essay on the Objectivity of Law', in B. Bix (ed) Analyzing Law, (Oxford, OUP, 1998), R. Rorty, 'The Banality of Pragmatism and the Poetry of Justice', in Brint and Weaver, eds, Pragmatism in Law and Society, (Westview Press, 1991), H. Putnam, 'Are Moral and Legal Values Made or Discovered?' 1 Legal Theory, 1995, 5.

3 I refer here to legal realism not the metaphysical variety. Brian Leiter has defended the view that realist jurisprudence should be viewed as being based on philosophical naturalism. While this is not the place for an analysis of Leiter's sophisticated arguments, I suggest that the dominant concern of the legal realists was in fact to point to the redundancy of philosophy in law but in any case Leiter's theory relates better to the Scandinavian realists than to those in the U.S., such as Frank and Holmes (see B. Leiter, 'Naturalism and Naturalized Jurisprudence' in Bix, op cit $\mathrm{n} 2$.

4 See for example: J Gordley, 'Tort Law in the Aristotelian Tradition', and R.W. Wright, 'Right, Justice and Tort Law' both in D.G. Owen (ed), Philosophical Foundations of the Law of Tort, (Oxford, OUP, 1995). 
resonates with critical legal perspectives ${ }^{5}$ such as legal feminism and critical race theory which concede very little natural determinacy in law. However, it is appropriate also to include within this second view those writers who combine a belief in law's conventional or 'constructivist' character with a belief that law has a high level of internal, principled consistency akin to 'objectivity'. ${ }^{6}$ While some may be happy to use the label 'natural law' in relation to certain writers in this latter camp ${ }^{7}$, it shall appear that I take a true position of natural law to be claiming a more substantial sense of objectivity ${ }^{8}$, such that law is expressive of conformity to a natural order of events which imposes order on legal reasoning.

According to the philosophers, and not unreasonably, we cannot believe that law is expressive of a deeper, or 'out there' ${ }^{\text {o }}$ order and, at the same time, that it is an artificial construct created by judges. And yet for those who immerse themselves in case law a blend of these perspectives would seem quite near to the truth of the matter. There seems to be a clear order to legal reasoning that is beyond artifice, and independent of convention, such that experienced judges talk about their intuitive sense of what is demanded by the facts of a particular case. Part of this demand comes from the legislative and case law context but it is perhaps more accurate to say that it comes from the situation or context of the adjudication. To explain this demand according to convention or 'shared conviction' (for example, of liberal morality) subtly downgrades our sense that the contexts of adjudication are 'real' 10 , that the circumstances of case law exert a strong pull which cannot properly be labelled merely as shared belief about liberal political values, economics or whatever. At the same time it does seem odd to modern sensibilities to talk about a metaphysical realm of objective virtue, essences or dispositions underlying legal reasoning. After all, Aristotle viewed slavery as a natural institution, and Dicey in his Law of the Constitution described the case against women's suffrage as "conforming to the nature of things" 11 , and this seems to suggest to many that any form of naturalist essentialism is destined to lead to bigotry. As usual therefore, the alternatives offered to lawyers by the philosophers seem to miss our sense of the distinctive character of legal

5 It is perhaps a little problematic to characterise legal realism in similar terms because leading realists asserted both that legal reasoning is highly artificial and yet potentially determinate, e.g. by reference to notions such as situation sensitivity (see K. Llewellyn, The Common Law Tradition, (Little Brown \& Co, 1960)).

6 The most famous of such theorists of course being Dworkin but in a slightly more idiosyncratic way than those adopting the insights of philosophers such as Putnam (see references to Marmor in $\mathrm{n} 2$ above). Dworkin would perhaps deny that one has to make the choice between a constructed and a 'real' form of objectivity, since any notion of 'real' objectivity is a hoax (see his 'Objectivity and Truth: You'd Better Believe It', 25 Philosophy and Public Affairs 87 (1996), and see Rorty op cit $\mathrm{n} 2$.

7 See discussion of how to characterise Dworkin in this regard in A.J. Lisska, Aquinas's Theory of Natural Law, (Oxford, OUP, 1996), at p34.

8 See discussion in section four of this article.

9 See articles referred to in $\mathrm{n} 2$ above.

10 Brian Tamanaha offers a very good defence of the role of realism in law, on the foundations of Deweyan pragmatism (B. Tamanaha, Realistic Socio-Legal Theory, (Oxford, OUP, 1997), and see my critique of his arguments 'Is There a Proper Subject Matter for Socio-Legal Studies?', 18 Oxford Journal of Legal Studies 1998, 707.

11 A.V. Dicey, The Law of the Constitution, (London: Macmillan, $8^{\text {th }}$ ed, 1926), Introduction, p lxvi. 
reasoning. In particular, we are not permitted a version of natural law thinking which points to a real order beneath judicial decision but which is compatible with the belief that legal reasoning is, in important senses, artificial. $^{12}$

This article seeks to suggest and develop in outline form this version of natural law, based upon a strong form of particularism and a belief in the objectivity of legal situations. Particularism ${ }^{13}$ applied to law is the idea that the properties which are relevant to judicial decision in particular instances of adjudication are not generally relevant in adjudication, that is, properties which make a difference in the resolution of a particular case should not be understood to generally make a difference in the resolution of cases. While modern particularism advances considerably the legal realist project, it is in the same spirit, and would support statements such as Llewellyn's that "everything" said by a judge in a case is to "be read with primary reference to the particular dispute, the particular question before him", 14 and of Jerome Frank that "[u]ntil a court has passed on those (that is, a particular set of) facts no law on that subject is yet in existence". ${ }^{15}$ Particularism points to the way that in law the very same features of a situation which are a reason for $X$ in one case may be no reason, or indeed a reason against $\mathrm{X}$ in another case. By contrast, generalists see the law as ordered according to general evaluative considerations, most notably principles, under which the facts of particular adjudications can be subsumed. ${ }^{16}$ The essential difference between particularists and generalists is that generalists believe that all the factors which may explain why reasons apply differently in different cases could be added in to a general formula which would be able to act as a guide to the determination of disputes. Particularists reject this as being hopelessly non-specific in that there are just too many factors of context to add in for the generalist project to be redeemable. More importantly, particularists claim that an intelligible notion of value does not require any form of generalism: it does not matter that the only explanations of what is an appropriate resolution of a case are limited to that particular case. For our purposes it is significant that positions of natural law have always been assumed to be inextricably linked to a discourse of impersonal and generalist moral principle, and thus seen as incompatible with positions linked to the agenda of critical legal theory.

12 Such a view might be attractive to those modern critical legal theorists who while stressing the dominance of context over principle still believe that there are more sensitive responses to context (i.e. that some accounts of context are 'way off'), and that there are ways of failing to be sensitive to context in law. See discussion in sections three and four of this article.

13 See J Dancy, Moral Reasons, (Oxford, Blackwell, 1993), J Dancy, 'Ethical Particularism and Morally Relevant Properties', Mind (1983), Vol. XCII, 530, J Dancy, 'Why There is Really No Such Thing as the Theory of Motivation' Presidential Address, Proceedings of the Aristotelian Society, October 1994 See my attempt to apply Dancy's particularism to law; 'Reason, Cause and Principle in Law: The Normativity of Context', 19 Oxford Journal of Legal Studies 1999, 203.

14 K N Llewellyn, The Bramble Bush, (1930, Oceana Edition) p42. Emphasis in the original.

15 J Frank, Law and The Modern Mind, (New York: Brentano, 1930), at p46. Words in parentheses are mine.

16 There are distinct types of generalist argument, broadly divided into the prima facie and absolutist forms. See J Dancy, Moral Reasons, op cit n 13, at p180. 
The essay is in four sections. In the first, I argue that a position of natural law does not have to be tied to generalism. I put forward a particularist account of law as the basis for a modern form of natural law thinking. The second section examines in more detail the application of particularism to legal theory, and some of the objections. In the third section I discuss the role that the concept of 'intuition' might play in this model. Broadly, I wish to defend a greater role for intuition than has been fashionable in legal theory for many years. Lastly, I discuss the sense in which particular intuitions about law can be objective: I claim that such intuitions are objective since they derive from the real and inevitable demands of context in particular cases. A subsidiary aim of the analysis, and one which is not developed here, is tentatively to offer radical particularism as a theoretical foundation for modern critical legal theory (given its acknowledgement of the situatedness of legal problems in the middle of local human concerns), and moreover to present this as a better foundation for critical legal theory than the currently fashionable deconstructive or sociological perspectives. ${ }^{17}$

\section{PARTICULARISM AND NATURAL LAW}

I want to say that the law is discovered not created, that it has order, but that it is also a response to the complex particularities of life which are thrown up in case law. Traditional ${ }^{18}$ natural lawyers might argue that there is nothing new in this, since there has always been room for the particularities of life to be accommodated within a traditional natural law approach. They might argue, in Aristotelian terms, for a set of dispositional properties embedded in human nature which tend towards the perfection of their end, and which contribute to 'proper' human flourishing. So, just as an acorn thankfully cannot grow up to be a management consultant but must become an oak tree, we too should identify those dispositions that contribute to our 'proper' flourishing as human beings. Legal reasoning can then play its role by acting as one means to the practical encouragement of virtues, such as wisdom and justice, which conduce or incline to the maturation of the dispositions. This account leaves room for a high level of discretion, or determination, 19 of the requirements of the virtues in individual cases (we recall here Aquinas' analogy of the housebuilder who dictates the structure of the house but not the placement of individual features such as doors and windows). It is of course doubtful that, even could we agree on them, the 'virtues' which are said to be conducive to proper human development would speak to many modern lifestyles. A more fundamental problem however is the old chestnut of the so called 'naturalistic fallacy', since it appears that evaluative judgements, about what ought to be done, ${ }^{20}$ or what is the virtuous aspect of a disposition, are being made on the basis of facts about human nature, about what is a natural disposition.

Aware of this difficulty, contemporary natural lawyers such as Finnis have sought to retain Aristotelian notions and to accept the force of the naturalistic fallacy by locating the basic goods of human striving

17 Particularism is presented here as an alternative basis to both the Derridean and Habermasian bases of modern critical legal theory. For a good, recent, discussion of these rival bases for critical legal theory see M Rosenfeld, Just Interpretations: Law Between Ethics and Politics, (California, University of California Press, 1999).

18 See discussion in Lisska, op cit $\mathrm{n} 7$ at pp 198-9.

19 This was the term used by Aquinas: see Question 91, Article 3, of Aquinas' Summa Theologiae, translated in part in Lisska, op cit $\mathrm{n} 7$ at $\mathrm{p} 260$.

20 See Jabbari op cit $\mathrm{n} 13$, at pp 215-225. 
somewhere other than in the realm of human nature. Instead the natural law originates in speculative knowledge of an underived and self-evident realm concerning those things which are goods for human beings. ${ }^{21}$ The knowledge of these basic human goods is not derived from facts about human nature but is regarded by Finnis as self-evident, and it is an exercise in deduction to obtain moral precepts from the basic goods. This is not to be seen as problematic, since it would be pointless to deny that the proposition "killing is wrong" flows directly from the self-evidence of life as a basic component of human flourishing. Yet arguably Finnis' solution pays a price in terms of the concreteness, or particularity, of natural law. The problem lies in understanding the relation between the precepts of natural law and practice, ${ }^{22}$ since, as I shall argue below, Finnis' account weakens the ability of natural law precepts to be understood as guides to action in the particular contexts of the law's regulation of human affairs. In this respect the traditional natural law theory of Aquinas, which links natural law to human dispositions, offers a more convincing account of the process of practical reasoning, that is, from a concrete human disposition to the particularities of life. ${ }^{23}$ It is, in simple terms, a more grounded and particularistic account of the role of natural law than is provided in Finnis' theory. Yet even traditional natural law theory suffers from excessive generalism in that it stresses the dominance of the general, for example, 'proper' human dispositions, primary precepts of natural law and so forth, over the particular characteristics of context. The problem for all variants of existing natural law, traditional or modern, is their identification of the natural law with a fairly narrow set of general evaluative considerations, within which the particularities of life may be subsumed (or alternatively treated as a 'corruption' of the natural law).

To elaborate on these points, consider more closely Finnis' depiction of law as a means of rationally pursuing basic human goods. ${ }^{24}$ Does Finnis truly demonstrate how underived basic goods, and the abstract precepts deduced from them, can be understood to have a role in guiding the resolution of concrete, particular, disputes? While we may concede Finnis' account of the derivation of the basic precepts of natural law from the basic goods, why should we concede that the precepts have sufficient content to determine the resolution of particular disputes? Indeed, leading scholars on Aquinas, such as Lisska, have commented that Finnis could be argued to have neglected the traditional natural law preoccupation with practical reasoning since his account is more concerned with forms of self-evident knowledge, pieces of knowing than of doing. ${ }^{25}$ As Lisska

21 See J. Finnis, Natural Law and Natural Rights (Oxford, OUP, 1980), chaps 2,3 and 4.

22 See the excellent analysis in Lisska, op cit n 7, chap 6. Lisska discusses the arguments of Veatch that Finnis' approach to natural law lacks a proper ontological foundation.

23 See Lisska, op cit $\mathrm{n} 7$, on how Aquinas viewed the application of principles to situations (pp 253-54). Lisska seems to suggest that Aquinas is engaging in a form of radical particularism but this seems hard to square with the implicit governing role for precepts which we find in Aquinas, and which is clearly evident in Finnis' treatment of Aquinas' notion of determination (see J.M Finnis, Natural Law and Natural Rights (OUP, 1980), pp 284-286). I reach no conclusion on this since if Lisska is correct then there is a clear bridge between the argument in this article and the traditional natural law of Aquinas and Aristotle. See further discussion of this in $\mathrm{n} 42$ below.

24 See Finnis op cit n 21. Refer also to his use of Aquinas' notion of determinatio, at $\mathrm{pp}$ 284-9.

25 Lisska, op cit n 7, at p 156. 
further points out, since the Aristotelian notion of practical reason concerns actions to be undertaken, not a knowledge of ends, Finnis could be said to blur the distinction. ${ }^{26}$ What I find lacking in Finnis, as in all other general moralists in law, is a convincing account of how precepts such as "one should not destroy life" can be understood to operate to demand particular outcomes within the craft of law. An example I use later is the English House of Lords' case of Bland ${ }^{27}$ which concerned the legality of discontinuing a regime of nutrition and medication for a patient in a persistent vegetative state (PVS). Can it truly be said that knowing life to be a basic good, and recognising the principle "thou shalt not kill" can be understood to guide us in complex cases such as these? For so long as we have non-controversial answers to questions such as "does this particular state constitute 'life'?" or "should the ending of nutrition in these circumstances be seen as 'killing'?" then the purity, in the sense of the lack of dependence of natural law on considerations of fact, in Finnis' model remains intact. But of course law by its very regulation of complex matrices of fact does not provide this: it is par excellence the realm of controversy. Finnis is driven to treat the subsumption of particular cases within general principles as being relatively unproblematic, and this is why all such moralists are far happier with hypothetical cases. The sleight of hand used by the moralists is to demonstrate coherence between precept and outcome in the area of hypothetical or imaginary cases ${ }^{28}$ rather than to reach conclusions in the realm of particular cases. Hypothetical cases are of course very convenient since one can so frame the facts to fit the principles, and their abuse by natural lawyers is only one instance of widespread abuse of the concept of principles in this way in legal theory. I shall argue in the next section that as well as being of limited explanatory weight, the generalism of writers such as Finnis should be seen as a morally bankrupt approach to the justification of decision.

A large part of the difficulty here is understanding what is meant when we speak of law as a species of practical reasoning. Practical reasoning is said to apply to law because it is reasoning concerning things to be done not the objects of theoretical or speculative knowledge. There does, however, seem to be genuine room for disagreement concerning the meaning of Aristotle's remarks in the The Nicomachean Ethics concerning practical reasoning, ${ }^{29}$ and in particular their implication for law. What needs to be clearly debated is whether law is best understood as a form of reasoning concerning particular moral objects or whether it is reasoning concerning practical knowledge. In the realm of knowledge concerning things to be done Aristotle distinguished ${ }^{30}$ between productive knowledge and practical knowledge. The key difference here surrounds the objects or telos of these activities. In the case of productive knowledge the objects of the activity should not be seen as identical with the activity, that is to say they are external objects. So for example the sculptor can use his productive knowledge or skill to carve a figure. The external object, that is, the figure, is clearly separate from the carving. But in the case of practical knowledge, Aristotle invites us to see that the objects of knowledge are directly linked with the activity itself, becoming manifest in the activity. Any objects internal to the activity will be judged and

26 ibid at $\mathrm{p} 156$.

27 Airedale NHS Trust v Bland [1993] 1 All ER 859

28 See Finnis' discussion of the law of bankruptcy, in Finnis op cit n 21 at p 188.

29 See Finnis, op cit $\mathrm{n} 21$, at pp 20 and 77, and Lisska op cit $\mathrm{n} 7$, at $\mathrm{p} 156$. Finnis is less than clear on this point (op cit $\mathrm{n} 21$ at $\mathrm{p} 20$ ).

30 I am indebted to Professor Matti Niemi of the Faculty of Law, University of Lapland for his comments, in an unpublished paper on Aristotle, derived from Aristotle's Nicomachean Ethics, 1139a, 1139b and 1140 b. 
evaluated from within the activity. While it is assumed in principle-based approaches that practical reasoning in law must be towards some form of external object, I would argue that the notion of 'practical knowledge' described above is the best analogy for legal reasoning. In adjudication we see law as a craft with a clear internal dynamic unconnected to the attainment of any preconceived outcome. The primary value is the craft and the destination is merely the result of the diligent exercise of the craft. This pre-eminence of activity is the true meaning of practical reasoning in law.

The real obstacle in generating a modern natural law, which is properly sensitive to the unique and real demands of modern life, is therefore generalism. Specifically, it is the assumption that the properties which are relevant to judicial decision in particular instances of adjudication are generally relevant in adjudication, that there is a scheme of external objects which guide and structure judicial reasoning. This generalist view can be contrasted with a particularism which, as noted in the introduction to this essay, holds that properties which make a difference in a particular case should not be seen as generally making a difference, that the behaviour of a reason in a new case cannot be predicted from its behaviour elsewhere. ${ }^{31}$ Putting it in other words, the dynamic of reasons in law is internal to the craft. Applying particularism at its simplest level to law, we might point to the way that legal principles, derived from broad moral principles, such as "no one should profit from their own wrong" might in one case be a reason to invalidate a will and in another a reason to affirm it, and thus conclude that principles have little role in legal reasoning. ${ }^{32}$ While this is a valuable insight, a more sophisticated form of particularism would point to the way that in law the very same features of a situation which are taken as a reason for $\mathrm{X}$ in one case may be no reason, or a reason against $\mathrm{X}$ in another case. ${ }^{33}$ To take perhaps an over simple example, the fact that plaintiff and defendant are in a relation of 'proximity' might be a reason for imposing a duty of care in one case (for example, between doctor and patient), and yet in another 'proximity' might be the very reason for not imposing a duty of care (for example, in relation to domestic relationships between a husband and wife in the home). Take as a further example the fact that a minor has "sufficient understanding and intelligence to be capable of making up his own mind" ${ }^{34}$ This might be a reason to grant the child capacity to consent to medical treatment in one case but in another might function as a reason against the grant of capacity. For example in $R e E$ a case concerning the right of a 15 year old Jehovah's Witness to refuse a blood transfusion for the treatment of his leukaemia, it was said that the clear intelligence and understanding that had led $\mathrm{E}$ to resolve so firmly to make up his mind against a transfusion demonstrated that he could not truly be capable of

31 See Dancy, Moral Reasons, op cit n 13, at p 60. Also see, J Dancy, 'Ethical Particularism and Morally Relevant Properties', op cit $\mathrm{n} 13$, at $\mathrm{p} 534$.

32 Dancy gives the example of borrowing a book from someone and then finding out later that it has been stolen. Normally the fact that the book has been borrowed is a reason for returning it to the person from whom it was borrowed, but not here: see J Dancy, Moral Reasons, op cit $\mathrm{n}$ 13, at pp 60-61.

33 Dancy gives the example of sending an article to a journal on the grounds that since they have published the author's work before that is a reason to publish a further piece. In the example, this turns out to be a reason not to publish a further piece: see J Dancy, Moral Reasons, op cit $\mathrm{n}$ 13, at $\mathrm{p} 62$.

34 The formula for the test of mental capacity of minors in English law: see House of Lords in Gillick v West Norfolk and Wisbech Area Health Authority [1985] 3 All ER 402. 
refusing consent to the treatment, on grounds that it revealed an inability to appreciate the implications of the refusal..$^{35}$

It is thus that particularism questions the extent to which traditional principle-based theories really capture the irreducible complexity of practical legal situations. This is clearly linked to the earlier discussion concerning law's status as practical knowledge with its own internal objects. Take as a further example the case of Merrell Dow v Norton, ${ }^{36}$ in which the House of Lords held a patent for a metabolite of terfenadine to be lacking in novelty (one requirement for a valid patent) on the grounds that the prior patent for terfenadine itself had revealed all the essential features of the 'invention'. This was despite an acceptance by the House of Lords of the earlier European Patent Office decision in Mobil ${ }^{37}$ which had held that the details of a patent are not to be regarded as lacking in novelty unless they have been clearly communicated to the public, that is, it is not enough that the details were inherent in the prior use they must be clearly communicated to the public. In Mobil, the patent concerned the discovery of friction-reducing properties in an additive to engine oils, which additive had already been included and sold to the public in engine oils as a rust-preventing agent. The Mobil principle makes perfect sense: something cannot be said to be known until it has been communicated to the world, and the principle would therefore seem to require clear public disclosure as a general pre-condition to a finding of lack of novelty. The problem in Mobil was that the discovery was of a new advantage to a known substance already present in engine oil available to the public. Hence, the absurd result that people could be stopped from using their engine oil when they have friction-reducing intent rather than the legitimate rust-preventing one. The House of Lords' reluctance to follow Mobil demonstrates a belief that principles (in this case that novelty is only destroyed by prior communication) can make sense in themselves but have no sensible application to the complex particularities of life. This should be seen as a fundamental conceptual difficulty with the notion that the world of fact is subsumed under a realm of principle, and the problem is not eased by regarding principles as having a pro tanto or prima facie form. ${ }^{38}$

The challenge of particularism in legal theory then is to point to the way that actual cases always outrun the capacity of general considerations to account for them. This is not to be treated as requiring some small modification of generalism so that it can better demonstrate the governing role of principle ${ }^{39}$. Rather it points to the inadequacy of generalism for most important purposes ${ }^{40}$ in legal theory. The accusations of generalism are however less stringent when applied to the older versions of natural law. Aristotelian essentialism builds value directly into nature: it does not rest on the idea of a realm of general value being applied to an inert world

35 Re E (A Minor) [1992] 2 FCR 219. It might be said that this case merely shows that $\mathrm{E}$ lacked understanding, and clearly Ward J covers this possibility in his own conclusion. But it seems reasonable to interpret the case as saying that the ability to make up one's mind decisively with full understanding indicates a lack of capacity since a reasonable person would not reach this conclusion.

36 [1995] RPC 233

37 MOBIL/Friction reducing additive [1990] EPOR 73

38 See Dancy's dismissal of prima facie forms of generalism: J. Dancy, Moral Reasons, op cit $\mathrm{n} 13$, at pp 92-100.

39 See ibid.

40 See Jabbari, op cit $\mathrm{n} 13$, at pp 233-4, stressing that principles have $a$ role in legal education and that the arguments against their use must be carefully understood. 
of natural fact. ${ }^{41}$ On Aristotle's account practical reasoning is a very concrete form of reasoning centred on natural human dispositions and virtues by people who possess wisdom and sensitivity to experience. Similarly in Aquinas who, while avoiding any statement that natural law was to be identified with the detailed particularities of judgement ${ }^{42}$, retains the notion of determination as a good, earthy means of depicting how the requirements of natural law may be instantiated in individual cases. The dispositional basis of Aquinas' natural law lends itself to particular statements about the good in human affairs, so that we might for example be able to derive a good deal of practical significance from statements such as "just people will listen to both sides of an argument", or "only greedy people enjoy excessive remuneration from high office in a company". These are the kind of statements which Finnis avoids making because they call upon observations concerning the good in particular factual contexts, not what is self-evident or deduced from self-evident propositions. Finnis' version of natural law doesn't really touch the particularities of life or show how we can understand judicial decision to be guided by natural law, and one might go further and say that his use of determination is significantly different in this respect from that of Aquinas'. A better rendering of determination would be to emphasise context over principle, of earthiness over high-sounding detachment. Such a version of natural law would move away from principle to an interest in the way that life's situations impose normative demands on decisionmakers: it moves us to a renewed interest in the natural in natural law.

The assumption of an inevitable link between natural law and generalist factors, such as principles, dispositions, basic forms of good and so forth, has been questioned. It is of course further assumed that the objectivity in a position of natural law derives from generalism (this is the subject of section four below). I wish to develop an alternative form of natural law, based upon particularism, which is not tied to assumptions about the facts of human nature, abstract principles of theoretical reason, or causal relations. Whereas the focus of traditional natural law is on development and perfection of basic goods, a particularist finds the 'virtue' of a decision in the matrix of the facts and context which make up that particular decision. These unique facts are reasons and thus do not need to

41 See Lisska, op cit $\mathrm{n} 7$, p 163.

42 The relation between the general and the particular in Aquinas is not clear cut. Aquinas clearly stressed the importance of particularity, as can be seen from this quote from his Commentary on the Nichomachean Ethics: “.... moral judgement in particular cases is left to the prudence of each moral agent. The moral agent, in acting prudently, must attentively consider the action to be undertaken at the present time, but only after all the particular circumstances have been taken into consideration", quoted in Lisska op cit n 7 at p 259. But how far can this go without losing the guiding role of the natural law (whether conceived of in terms of basic goods or natural dispositions)? Lisska presents Aquinas as a 'radical particularist': "There is radical particularity in Aristotle and Aquinas involving moral situations that is opposed theoretically to the rulebound directives of most post-Enlightenment moral theory. This radical contingency of Aristotelian and Aquinian moral theory should not be forgotten in the process of developing a consistent theory of natural law. What one has in this reconstructed account of Aquinas' natural law theory is a balanced account of existentialist subjectivity within the context of a dispositional theory of human nature", at $\mathrm{p} 253$. Since I am sympathetic to Aquinas I am happy to accept this interpretation (see point in $\mathrm{n} 23$ above): I merely wish to suggest certain difficulties in stressing the 'existential' component of moral choice given Aquinas' broader conception of the natural law. 
draw their 'normativity' from essences, dispositions or abstract (Kantian) theoretical precepts. This approach has the courage to be intuitionistic ${ }^{43}$ since it does not need to infer or derive the requirements for decision from anything other than the kinds of circumstances which are found in particular cases. Interestingly, this kind of intuition can claim to be objective in the sense that we require, and in the sense in which generalist legal theory cannot, since it furnishes an answer that is absolutely appropriate in these circumstances. Moreover, since these precise circumstances should be understood to be unrepeatable there is nothing more absolute that such a theory stands as a pale reflection to. These points are developed in sections three and four below.

Put in a more simple way, my argument is that it is best not to see legal reality as a terrain of atoms ${ }^{44}$ of legal principle and atoms of brute fact, an inert ether in which normative significance is attached to brute facts by their conjugation with principles, precepts or rules. I prefer to dispense with Humean language for these purposes and identify legal reasons as emerging from, for want of a less imprecise term, an active background ${ }^{45}$ (or even less satisfactorily, a legal subconscious), which furnishes judges with a unique reason to decide a case one way rather than another ${ }^{46}$. Far

43 Lisska presents Finnis as being reliant on a form of moral intuitionism despite Finnis' denial of the this: "What is the structure of the 'practical grasp' which Finnis suggests is the 'primary grasp' of the basic goods?... Without an object for theoretical reason, it is unclear what else, despite his protestations to the contrary, Finnis might use for 'moral knowledge' but a form of intuition under the guise of practical reason", op cit $\mathrm{n} 7$ at $\mathrm{p} 158$.

44 A more extended discussion can be found in Jabbari, op cit $\mathrm{n}$ 13. This sense of atomism permits legal positivists in particular to continue to find further formal benchmarks or rules of recognition to anchor forms of 'black letter' scholarship, even extending this to less 'atomistic' constructs such as principles: see for example H.L.A. Hart, The Concept of Law, (Oxford, OUP, 2nd ed, 1994), p 247. The legal theorist who has come closest to a nonatomistic conception of legal reality, excluding the purer archaic forms of natural law found in for example Cicero or Grotius, is Ronald Dworkin in his use of principles to avoid the 'all-or-nothing' character of rules. It is important to recognise however that while rejecting atomism in parts (with the qualification that Hart, citing MacCormick, sees no difficulty in including principles within a rule of recognition), Dworkin's theory is still firmly rooted in certain basic Humean oppositions. He clearly regards the exercise of justification (in the elaborate architecture of law as integrity) as something separate from particular contexts of adjudication as constituted by the brute facts of cases and the motivation of judges. Despite the risk of oversimplification, Dworkin's principles must have an atomistic and generalist character if they are to be applied as justifications to the facts of cases, or if they are to be used to choose between legal rules: it is thus that they can be incorporated into a modified rule of recognition along with rules.

45 See more extended discussion of this in Jabbari, op cit $\mathrm{n} \mathrm{13.} \mathrm{This} \mathrm{is} \mathrm{not} \mathrm{an}$ argument that judicial decision-making consists of an indefinable mixture of normative and factual elements (so-called 'thick' concept) since the language of mixture still presents us with a Humean distinction between norm and fact, and leaves us with Hart's problem of attempting to both radically separate then to fuse the normative and the factual. For a philosophical analysis of the relevance of the concept of the background in social life see J.R. Searle, The Construction of Social Reality, (London, 1995).

46 Weinrib is defending a very similar argument, different in important respects to mine, in his 'Legal Formalism: On the Immanent Rationality of Law', 97 Yale 
from being inert, this background demands resolution in one way rather than another, and not by the mere inclinations of judges but often against them. The key concern is the detailed and active context of an adjudication, where we are able to discern the rationality or logic of a judicial decision, or the reason why the decision was reached, and the reason for the decision, that is the conscious rationalisation of the decision by the judge. ${ }^{47}$ This is a realm which transcends our taken-for-granted architecture of hermeneutics versus structuralism.

\section{PARTICULARISM VERSUS GENERALISM}

On one view of legal theory it does not matter that theory has nothing useful to say about the world. The order of ideas is completely separate from the order of events, and the fact that a proposition can have no bearing on events in the world is not significant as long as the proposition makes sense in semantic terms. For example, modern legal positivists who defend an 'incorporationist' thesis, so-called 'inclusive legal positivism', seem unconcerned that a rule of recognition which incorporates moral principles need only be understood to be capable of guiding action rather than actually being able to offer guidance to concrete action by officials. To the extent that legal philosophers are concerned with individual rules or principles of law, the same disinterest in practicality reigns (or perhaps it would be more accurate to say that this disinterest is mandated by the theorists' belief in the priority of the conceptual, in its autonomy from matters of fact). Hence the fact that a rule or principle of a general character, such as "no one should profit from their own wrong", is a factor which under-determines the outcome of a particular case, providing no concrete guidance to a judge, does not matter as long as we can understand the meaning of the sentence as being potentially a guide to conduct. The question of course is: how can something which cannot be shown to be a determining guide to conduct in particular cases be so in a 'semantic' sense? Or, to put it another way, does the sentence still have any meaning which is of value in legal theory? Along with the realists, I would answer no, and this is perhaps the fundamental division of view in modern legal theory.

The basic problems of explanation that result from generalism were the subject of section one. Let us move to the issue of justification, ${ }^{48}$ and return to the point made earlier concerning the moral bankruptcy of generalism. It should not be thought that generalist arguments, based upon principles for example, have some form of monopoly on moral force. Many modern legal theorists accord a privilege to the 'local' (whether these be considerations of race, gender or sexual identity) in assigning ethical value to decision. Minow and Spelman convey the attraction of a more particularist argument concerning 'context' extremely well:

"Context ... represents the acknowledgement of the situatedness of human beings who know, argue, justify, and judge. Rather than a weakness or a departure from the ideal of distance and impersonality, acknowledging the human situation and the location of a problem in the midst of communities of actual people with views about it is a precondition of honesty in human judgements. Ultimately, the attention to the varieties of contexts for judgement helps to focus on human intelligence, the thinking, creating,

Law Journal (1989), 949. The concept of 'immanent rationality' is a good one: the question concerns the nature of that rationality.

47 See further discussion of this in Jabbari, op cit $\mathrm{n} 13$.

48 See references to Dancy's writings in $\mathrm{n} \mathrm{13}$, in particular his 'Why There is Really No Such Thing as the Theory of Motivation'. 
responding parts of human beings, drawn out by the task of making decisions about how to live and treat others." 49

These kinds of sentiments demand that we question the moral force of the ethic that demands fidelity to principle in the face of compelling circumstance ${ }^{50} \mathrm{~A}$ good illustration of this is found in those commentators, such as Keown and Finnis, who criticise the decision in Bland for weakening the principle of the sanctity of life. For such writers the law becomes 'misshapen', intellectually and morally, if this principle is weakened (despite the fact that medical law has never adhered to any such principle). ${ }^{51}$ It is, I think, significant that these high-sounding moral arguments are never directed at the particular individuals in extremis in these cases nor their family and their dilemmas, and it is never suggested directly that the family is acting wrongly in the circumstances. The real crime is the violation of abstract principle, despite the almost outrageous lack of compassion and the clear lack of governing weight of the principle of sanctity of life in the circumstances. Particularists reject the view that principles or rules can account for the moral force of judicial reasons: they believe that such force derives from sensitivity to facts. Further, they claim that the generalist, the "Man of Principle" is a harsh individual who accords more moral value to consistency than to a response to the demands of context.

The leading philosophical exponent of particularism is Jonathan Dancy. As Dancy concisely puts it, the question is not "Which other cases does this one best resemble?", but rather "What is the nature of the case before us?." While settled understandings, experience and other factors may be relevant, the crucial question is how things are in the case before us. The danger in generalism for Dancy is manifested in the sort of person who refuses to make a decision that the facts call for because of a desire to achieve consistency with a decision made on quite a different occasion, or to ensure consistency with established principles. In particularism, moral principles are reminders of the sort of importance a property can have in suitable circumstances, and hence particularism weakens the usefulness of imaginary cases, since "we would have already to have the sort of understanding of the actual case we were trying to use the imaginary one to achieve". 52 The crucial point on justification therefore is to attack the idea that justification:

"[can] only consist in the subsumption of this case under some general principle which commands rational support in some way or other. Since description is clearly not intended to achieve any such thing, description is

49 M. Minow and E.V. Spelman, 'In Context', in M. Brint and M. Weaver, eds, Pragmatism in Law and Society, (Westview Press, 1991), at p 269.

50 For a defence of a more particularist ethic see the writings of E. Levinas. A good introduction is S. Hand, The Levinas Reader (Oxford, Blackwell, 1989).

51 See J. Keown, 'Restoring Moral and Intellectual Shape to the Law After Bland', (1997) 113 LQR 482, and J.M. Finnis, 'Bland: Crossing the Rubicon?' (1993) 109 LQR 329. Countless examples could be given of the failure of the law in this area to give unequivocal support to the principles of sanctity of life. This is not just to point to obvious areas such as abortion and embryo research but to cases which had they not taken place in a medical context would almost certainly amount to murder or manslaughter, eg $R$ v Adams [1957] CLR 365 (concerning the legality of administering lethal doses of pain killers with a predominantly therapeutic intent) and $R e J$ [1990] 3 All ER 930 (concerning the legality of terminating treatment in the case of a profoundly handicapped baby).

52 J Dancy, Moral Reasons, op cit n 13 at p 69. 
one thing and justification another. I reject this account of justification, and with it the distinction between justification and description (my emphasis). To justify one's choice is to give the reasons one sees for making it, and to give those reasons is just to lay out how one sees the situation, starting in the right place and going on to display the various salient features in the right way; to do this is to fill in the moral horizon. The persuasiveness here is the persuasiveness of narrative: an internal coherence in the account which compels assent. We succeed in our aim when our story sounds right. Moral justification is therefore not subsumptive in nature, but narrative." 53

There is much in this account that offers to provide a theoretical infrastructure for modern critical legal theory. Turning our backs on the 'formalist' and Dworkinian view that the value of law is consistency with previous decisions or principle, we can require judges to be consistently sensitive to the features of individual cases in mature and intelligent ways. The Dworkinian idea of an unfolding, but unified, discourse can be rejected in favour of a consistency based upon the demands of context. Clearly there is a good deal of working out of the implications for law in this view but the direction of the argument is clear. ${ }^{54}$

We need to abandon the fiction that the normative, or reason-giving, element in law stands apart from the living context of judicial decision. All generalists have difficulty in accounting for this dimension in law, since the very nature of generalism is to point to normative factors standing apart from the decision, for example, rules or principles, which govern its resolution. Even Dworkin, despite his attempts to distinguish his 'constructive interpretation' from conventionalist or backward-looking theories, must concede that principles derived from past practice are applied to new situations. If not, he would be forced to take a step which he would not wish to take of saying that law comes into being only at the time of decision. It is thus that modern positivists are quite right to say that most Dworkinian principles can be incorporated into a reformed rule of recognition. ${ }^{55}$ The radical particularism which I defend has the courage to say that the law does in fact come into existence at the point of decision, that it is in the demands of particular contexts that the law comes into being. As Jerome Frank put it, endorsing a definition of law from the point of view of the 'lay person' which I have referred to earlier:

". . . the law, with respect to any particular set of facts, is a decision of a court with respect to those facts so far as that decision affects that particular person. Until a court has passed on those facts no law on that subject is yet in existence. Prior to such a decision, the only law available is the opinion of lawyers as to the law relating to that person and to those facts. Such opinion is not actually law but only a guess as to what a court will decide". 56

Dramatically this would seem to suggest that judges can never actually be wrong in their judgments. Of course it does not suggest any such thing, rather it suggests that the language of 'truth' and 'wrongness' is simply inappropriate when seeking to understand judicial decision, and that what we are truly talking about are degrees of sensitivity to the order in a

53 J Dancy, Moral Reasons, op cit $\mathrm{n} 13$ at $\mathrm{p} 113$.

54 See Jabbari op cit $\mathrm{n} 13$ for further discussion.

55 See Jules Coleman, 'Authority and Reason' in R.P. George, ed, The Autonomy of Law, (Oxford, OUP, 1996).

56 Jerome Frank op cit $\mathrm{n} 15$ at $\mathrm{p} 46$. 
particular context. Frank's invitation is not that we consider his view as an alternative theoretical understanding but rather that we see that reality constantly undermines theory. This surely is the true intent behind Holme's celebrated statement that the life of the law is not logic but experience, and this is a sentiment which stands in the way of attempts to provide a foundation for realist legal theory. ${ }^{57}$

Generalists will of course say that the above account does indeed mean that judicial decision can never be 'wrong', and furthermore that it is important to retain the ability to say that the balance of reasons that proved salient in the resolution of an issue, including the agent's reaction to them at the time, could have been different. This neglects the fact that what appears relevant later, for example on appeal, may include considerations based on the effect of the original decision in terms of its consequences: such information was not available to the decision-maker at the time of the decision. In other words, such reflection on other possibilities is only possible with hindsight, that is, after one has assessed the changes to circumstances made by the decision itself. If particularism is to be rigorous, we must resist the temptation to de-contextualise the dynamic nature of adjudication in order to compare it to non-particularised notions of right and wrong. I see reasons as emerging in contexts, and governing within contexts; I do not concede a place for general or presumptive ethical principles as determining legal outcomes. In my approach everything turns on the unique facts (combined normative/fact of the matter) ${ }^{58}$ of a particular adjudication. The label 'normative' should be used as an ex post facto rationalisation of judicial action; it ought not to be used to isolate exceptionless (or even presumptively applicable) ${ }^{59}$ normative facts apart from the detail of adjudication.

The critics, such as Raz, ${ }^{60}$ would perhaps claim that there must be general evaluative considerations if we are to retain the intelligibility of the notion of value and judgement. Without such considerations judicial decision making would be completely arbitrary. This reveals a good deal about the fundamentally different way in which the legal world is seen by analytical legal philosophers and those with a more realist slant. The question is why should the abandonment of general evaluative considerations lead to arbitrariness. Part of the response here is to point to the arguments mentioned earlier concerning the way in which arguments from principle seem insensitive, and thus in a sense arbitrary, to the morally compelling demands of context. But in addition, I would go further and accept fully that particularism to be consistent must abandon the intelligibility of value conceived as a general property. I would argue that consistency does not require generalism since a better meaning of consistency is to talk of judges being continually sensitive to the demands of context. Similarly, the realist notion of 'situation sense' describes well the consistency that can arise in the craft of law.

To put this in more abstract terms, an essential difference between particularists and generalists is that a generalist believes that all the factors which can explain why reasons apply differently in different cases can be added into a general formula which may act as a guide to action. Raz, in an analysis of Dancy's particularism, comments:

"Does not the intelligibility of value compel the rejection of particularism?

... The case for an affirmative answer lies in the thought that since

57 See $\mathrm{n} 3$ above.

58 See Jabbari op cit $\mathrm{n} 13$ for fuller discussion of this.

59 See $n 38$ above.

60 J. Raz, 'The Truth in Particularism' unpublished paper. 
regarding any evaluative concept and any two situations, if it applies to one and not to the other there is an explanation for this difference, it must be in principle possible to amass all the points which all these explanations may rely on and formulate one principle which sets a comprehensive and exceptionless rule for the use of that evaluative concept." ${ }^{\text {61 }}$

Characteristically Raz goes straight to the heart of the problem. He is correct to point to a tension in Dancy's particularism along the lines that Dancy regards reasons as general, that is, they are features of situations which can be instantiated on an indefinite number of occasions. As Raz comments, Dancy's view is particularist to the extent that the rightness of an action is not determined by the reasons which apply to the agent (that is, we need to know about the situation). Dancy does therefore seem to admit a gap between reasons for action and the evaluation of those reasons. That is to say, there must be a difference between two contexts which can explain why the same fact is a reason in one case and not a reason in another. Raz asks why therefore, if certain factors are relevant to the evaluation of action, are they not part of the reasons for or against it. As we know Dancy's response would be that this is bordering on fiction and is perhaps the most glaring weakness in generalism, in that it assumes that an agent can be understood to be guided by all the evaluatively relevant considerations in a situation. But Raz has a reasonable rejoinder which is that a person need not be consciously aware of their reasons for acting as long as the reasons are potentially citeable (that is, there is more to people's reasons than those factors which figure in their deliberations) ${ }^{62}$. Indeed, Raz accepts that the most rigorous form of particularism is linked to an absence of deliberation by the agent: the agent reacts to the situation in "all its concreteness":

"In some ways this view that reasons are concrete is more attractively particularistic than Dancy's thesis. On this view reasons are particular, not general as per Dancy. Being particular they cannot justify any other action (assuming that they are conclusive reasons for the action taken). But, unlike Dancy's reasons, they justify the action they are reasons for. No gap is allowed between the evaluative and the guiding function of evaluative considerations". ${ }^{63}$

This puts extremely well the version of particularism I am reaching for. While Raz accepts Dancy's rejection of this type of thesis on grounds of preservation of the intelligibility of reasons, I am happy to defend the nondeliberative approach, subject to some debate concerning the meaning of 'deliberation' and its implications for the concept of a 'reason' in law. I have argued elsewhere that subconscious responses to situations should not be viewed as potentially re-describable in terms of conscious ones. ${ }^{64}$ Rather, the logic of situations, and concrete responses made to them, requires a departure from our usual assumptions about the distance between the agent's reasons and a realm of inert fact 'beyond' those conscious reasoning processes.

61 Ibid at $\mathrm{p} 8$.

62 This requires analysis since it over-simplifies the nature of subconscious reasons: see Jabbari, op cit $\mathrm{n} 13$, pp 228-231.

63 See Raz op cit $\mathrm{n} 60$ at $\mathrm{p} 17$.

64 See Jabbari, op cit $\mathrm{n} 13$. 


\section{THE ORDER IN LAW AND THE ROLE OF INTUITION}

Although not the exclusive property of lawyers, 'intuition' can surely claim a place in the pantheon of 'legal concepts by adoption', alongside 'reasonableness' 'principles', 'rights' and so forth. It is not just that academic natural lawyers, calling upon Aristotle, have made natural reason a centre-piece of legal thought for over 2000 years, or that modern theorists such as Dworkin have made intuitive understanding (of principle) a central feature of adjudication. It is also that judges and those closest to them in the academy have accorded a special place to intuition, as the cement that holds together the legal universe, or as Cardozo put it quoting James "the total push and pressure of the cosmos which, when reasons are nicely balanced, must determine where choice shall fall" ${ }_{65}$ Intuition is a special friend of common lawyers who see something intangible beneath the mechanics of statute and rule, some means of bringing "experience of life and the structure of thought and belief " to bear on the exercise of discretion. ${ }^{66}$ In the context of this article, intuition captures well the living nature of decision which I am urging on the reader as part of a radical particularism. Yet, intuition has its problems. It can be a veil for prejudice, for example concealing controversial issues of sexual identity or national culture. A modern form of intuition would have to overcome these objections, and I can only hint at the direction of such an account in this article.

Any attempt to make intuition appealing to modern, not just medieval, sensibilities must address a number of key questions. In what situations does it make sense to talk of a role for judges' intuition? Is intuition in law close to pure contemplation, with the judge as prophet or seer making pronouncements by some infallible right of divination, or is it more structured? Perhaps the way out of some of the traditional reservations concerning the use of intuition is to focus a little less on divination, and more on the way in which the context of decision exerts a clear pull towards the intuitively correct answer. The traditional understanding is that if intuition has a role at all in law it is limited to an exercise in the excavation and application of principles to facts, in the working out of the requirements of the general for the particular. A more particularistic account of intuition clearly rejects this and must therefore address a key question: if intuition in law is not of principles, what is it intuition of ? Further, to what extent can this intuition be understood as an intuiting of objective features in adjudication (this is developed in section four)?

The broadest meaning which we can give to intuition, according to Rorty ${ }^{67}$ is "immediate apprehension", and he goes on to distinguish a number of distinct sub-senses of intuition. First, there is intuition as unjustified true belief not preceded by inference. This notion of a 'hunch' is not regarded as a theoretically important sense by philosophers. Second, there is intuition as immediate knowledge of the truth of a proposition: this is more significant theoretically. Third, intuition may refer to immediate knowledge of a concept, roughly "knowledge that does not entail an ability to define the concept". Lastly, there may be intuition as nonpropositional knowledge of an entity, knowledge that may be a necessary

65 B N Cardozo, The Nature of the Judicial Process, (Yale University Press, 1921), p 12.

66 Lord Radcliffe, Not In Feather Beds (Hamish Hamilton, 1968) at p 212.

67 Not to be confused with mathematical intuition or intuitionistic logic, both of which have separate specialised meanings. See R. Rorty 'Intuition' in Vol 4 The Encyclopaedia of Philosophy, ed P Edwards (Macmillan, New York, 1967). 
condition for, but not identical with, intuitive knowledge of the truth of propositions. Rorty distinguishes three sub-senses within this last category which exemplify this sense of intuition: (i) sense perceptions, considered as products of a cognitive faculty, (ii) intuitions of universals or of such insensible particulars as time and space, and (iii) inexpressible intuitions that, unlike sense perceptions and intutitions of universals, do not make possible knowledge of the truth of propositions about the entities intuited.

It is beyond the scope, and against the spirit, of this article to reflect on the conditions (viewed as semantic conventions) under which propositions of law can be viewed as being true. The notion of 'truth' is highly problematic when law is viewed in the way suggested in this article, with 'appropriateness' and 'sensitivity' being better words. The strong particularism argued for in this essay is perhaps closest to Rorty's second and third senses of intuition than the others, but I do not blanch at using the word 'hunch' in the context of legal reasoning in so far as it points to a non-intellectual discernment of appropriate responses to active situations. In giving meaning to this sense of intuition, we must bear in mind that, traditionally, accounts of intuition have been viewed as being inevitably based upon moral realism and foundationalism. It would after all make little sense to talk of intuition of factors which are themselves constructed by reasoning (for example, in relation to notions such as 'warranted assertibility'). But I would suggest very tentatively that it is possible to say that the significant properties in a practical context are intuited directly without endorsing foundationalism or the view that beliefs arising from intuition have direct justification in the moral realist sense. A particularist account of intuition would reject the view that intuition must be of generalist moral principles. Instead it would argue that the agent (judge) has a direct grasp of the demands of context in particular situations without the mediation of general reasons related to principles and so forth.

I have explained my account of the genesis of legal reasons in some depth elsewhere. ${ }^{68}$ I have there questioned the Humean and Cartesian structure of legal thought based on sharp divisions between the thinker and the world, and between norm and fact. I wished to question this view of human understanding as it was applied to law. On the first issue, I adapted to law the arguments of modern post-Humean philosophers, principally Dancy, in arguing that what judges believe about the facts of cases (that is, what is the case before them) can constitute complete reasons for judicial action. There is no need for a judicial desire to achieve $\mathrm{X}$ to be postulated, compounded with beliefs about norms or principles, and applied to an inert world of fact. On this account, the matrix of facts in adjudication can be called 'intrinsically motivating' 69 in that such facts are immediately intuited by judges as being a reason to resolve a case one way rather than another. I attempted to go further than many contemporary writers however on my approach to the second issue, the is/ought dichotomy, by suggesting that the facts in the judicial decision, are better not viewed as consisting in a mixture of normative matter, such as relevant legal rules or principles on the one hand, and of other pure facts of the matter, such as 'the damage was $£ 1.2$ million' on the other. Rather, my concept of a legal reason pointed to the way that this distinction, between normative and mere facts of the matter, fuses in the dynamic, practical contexts of adjudication. ${ }^{70}$ Of course, this distinction can be made, and many will be

68 Jabbari op cit $\mathrm{n} 13$.

69 See J Dancy, Moral Reasons, op cit $\mathrm{n} 13$ at $\mathrm{p} 24$.

70 See discussion concerning role of facts in moral reasons in $\mathbf{J}$ Dancy, Moral Reasons, op cit $\mathrm{n} 13$, at $\mathrm{p} 33$. 
reluctant to abandon it. But generally such distinctions can only be understood as rationalisations after the event of a particular judicial decision, when the factors which determined the outcome appear with hindsight to be clearly separate from those which did not. Principles, and other normative generalisations, which derive in this retrospective manner from adjudication furnish useful evidence to predict what the law might be in similar situations in the future, and can be useful in the teaching of novices. My essential point however was that they are not helpful in understanding, nor in teaching, what the law is in its proper determination.

Accordingly, one could say of case law that intuition of the order in a particular complex of facts is the reason for the choice of the formal reason given by the judge. The question is does this intuitive approach require a commitment to substantive moral aims, moral realism or principles, or does it require no more than an attitude of mature contemplation which is the property of people of reflective ability who can demonstrate sensitivity to the facts of cases? Is the community of legal expertise one of technical mastery, moral sensibility, or instinctual reflective ability? Although my argument is that the latter is the most accurate description of the essence of true ability in law it does leave the question of how we measure or 'grade' intuitions. I would argue that we need to abandon the notion that judges get cases 'wrong', in favour of a notion closer to 'sensitivity' or 'receptivity'. Rather like a radio which is 'poor' in its reception of a signal, some judges will not be as receptive or sensitive to the demands of context as others. Indeed, what offends people is not that judges get it 'wrong' but that they are insensitive to what the context facing the judge requires (stressing that legislative rules and principles derived from past cases will be an ever-present feature of the situation in which judges find themselves). True sensitivity requires an abandonment of all pre-conceptions about how the particularities of the case should be characterised. All forms of intellectualisation, of governing principles, stand in the way of allowing the order which is beyond thought to configure situations in appropriate ways. While Aquinas wanted to narrow the role that the inexpressible can play in natural law, the monastic tradition of Christianity has eschewed his intellectualism, ${ }^{71}$ as have other religious traditions. It is very difficult to express in words the sense of something which is beyond the oppositions of ordinary thought, and it is even more difficult to convince people that there can be anything of practical value in terms of practical reasoning to be derived from "nonintellectual understanding'. But this is a limited view. It neglects the manner in which decision arises from quiet contemplation, from stillness and a complete emptying of mind so that the individual may be directed to a proper response to context. In this realm the seeming incontestability of propositional logic, the basis of Western thought, is challenged by a logic of activity and place. ${ }^{72}$

As an aside on the religious foundations of natural law, clearly those wishing to defend a position of natural law derived from religious conviction will consider it important to see practical reasoning as being an attempt to give effect to ultimate values in human affairs. The Christian writers naturally see this in developmental terms, as Man proceeds slowly to salvation through History. However, it is important to appreciate that Christianity does not have a monopoly on natural law thinking, and that in other traditions of religious thought divinity is seen to be a fully realised

71 See Father Thomas Merton, Contemplative Prayer (Dalby, Longman \& Tood, 1993).

72 See N. Abe, 'Nishida's Philosophy of Place', Int. Philosophical Quarterly, 28, no 4, (Dec 1988) 355-371. 
potential of the universe in each moment of its unfolding. It should not be thought that the only credible attempt to defend a position of natural law is linked to hard and fast precepts for Man as a fallen being, tainted with original sin. Rather, natural law could be seen as an attempt to intuit directly the divine aspects which inhere in any practical context. In other words, what truly guides in a practical context, what steers towards the intuitively correct response, is not principle but the requirements of eternal order in that context. Such a position is firmly a position of natural law, since there are very clearly degrees of sensitivity to context and ways of failing to meet the requirements of order. This is not strictly an intellectual exercise but rather an attempt to penetrate beyond discriminative consciousness to the reality of things. There is a form of natural reason which derives from the submission of the discriminative consciousness to that which lies beyond it, and this has a role in law as much as in any other walk of life.

\section{OBJECTIVE, PARTICULAR INTUITIONS ABOUT LAW}

I have suggested that there is something real and objective in this modern conception of natural law. In this section I wish to suggest in very outline terms the view that the intuitive responses of judges to context can be seen to be grounded in the real demands of situations. Perhaps the most ambitious argument of this essay is that an account of judicial intuition, which claims to be a position of natural law, need not rest upon metaphysical (moral) principles, nor natural faculties, as the basis of that intuition. Judges have a direct intuition of the salient features in particular circumstances of case law, and these salient features are neither objective moral principles nor are they disciplining rules of interpretation/conditions of warranted assertibility. The objectivity here is in the precise circumstances of the case. What is recognised in judicial decision-making is real and objective, since what judges find therein is independent of their recognition of it in one sense (that is, there is a determinate order imposed by context). But this has to be qualified by the point that a proper understanding of recognition (as argued elsewhere ${ }^{73}$ ) points to the way that the judicial subconscious should not be seen as fundamentally separate from the terrain of 'fact' underlying context.

What does it mean to say that an intuition can be 'objective'? This entails some understanding of the usage of the term 'objectivity'. Marmor identifies a category of metaphysical objectivity which carries the commitment that there is a truth of the matter, that things are in the world as semantically objective statements describe. There is a difference between realism and objectivism, in that realism presumes the existence of an objective reality which is ontologically independent of our knowledge, whereas one can be an objectivist about kinds of objects which do not meet this condition of independence. Examples such as the rules of chess, speed limits and so forth show that objectivism does not entail the possibility of verification-transcendent truths. Much of the direction of this anti-realist approach to objectivity is derived from Putnam's writings on internal realism. For some time, there was disagreement between Putnam and the other key protagonist in the debate, Richard Rorty, over the extent to which the language of objectivity was appropriate to capture this antirealist sense of stability in judgement. Putnam had always maintained that being anti-realist and opposed to a correspondence theory of truth, as Rorty is, does not threaten the existence of a realm of knowledge about which one can use the language of objectivity, based upon the concept of

\footnotetext{
73 See Jabbari, op cit n 13 at pp 229-30.
} 
'warranted assertibility'. In similar vein, Dworkin ${ }^{74}$ has argued that since the idea of an 'Archimedean point' in ethics is illusory, we should have no difficulty in endorsing the language of objectivity (perhaps merely to sound a note of 'rigorism'). ${ }^{75}$ Marmor is critical of Dworkin's position, however, in that there seems no reason to take the absence of an Archimedean point as leading to objectivity, when it had led other such as Rorty to scepticism. ${ }^{76}$

It could reasonably be argued that Rorty seems to be winning in the contemporary debate. As Marmor has stated, Putnam has, in recent writings, changed his views on internal realism. Putnam's idea of warranted assertibility under ideal conditions was meant to remove the problem, identified by Rorty, that truth as correspondence requires us to have referential access to things 'out there' in the world. But, as Marmor 77 notes, Putnam realised that this was an illusory solution since "there is an equal problem related to the issue of how we can have referential or other access to "sufficiently good epistemic situations" ":

"[I]f the problem is that there is an interface between the 'knower' and the 'world', then this interface is still there, only shifted from the 'world' at large to the conditions which render a situation epistemically appropriate. This is mainly so because the idea of an ideal epistemic situation must be, as Putnam put it, 'a world involving notion'. If it is not, then we will be drawn very quickly to the highly implausible conclusion that the totality of human knowledge determines the totality of truths."

Rorty denies that there is a distinction between truth and justified belief: the notion of justified belief is the only option open to us. ${ }^{78}$

All of this has a very interesting application to an account of law based on intuition. We have seen that much of the talk about a tenable position of objectivity in law, which does not lapse into realism, turns on the identification of a realm of truths which remain recognition-dependent. However, we have seen that Putnam has conceded that this position of objectivity still requires an interface between the knower and the 'world' (in this case 'sufficiently good epistemic situations'), and that this retains some degree of recognition-independency. What all this seems to show is the impossibility of maintaining the Cartesian architecture of a world divided into the 'knower' and the 'known'. Elsewhere I have developed an argument along these lines in relation to the notion of the judicial subconscious, and have defended the view that reasons and causes are on a spectrum rather than independent oppositions ${ }^{79}$. I regard this as a significant movement beyond the limited intellectual architecture of contemporary critical legal theory.

Any talk of 'objectivity' of course risks perpetuating the Cartesian architecture. So how is it possible use the vocabulary of 'real' and 'objective' to refer to the demands of context in adjudication? One response is Dworkinian which is merely to mark a preference for the

74 See Dworkin op cit $\mathrm{n} 6$.

75 This is a pejorative point concerning Dworkin made by Rorty op cit $\mathrm{n} 2$ at $\mathrm{p} 89$.

76 See Marmor 'An Essay on the Objectivity of Law' op cit $\mathrm{n} 2$ at $\mathrm{p} 20$.

77 See ibid at $\mathrm{p} 28$. The quotation by Marmor is from H Putnam 'Sense, Nonsense and the Senses: An Inquiry into the Powers of the Human Mind', 91 The Journal of Philosophy (1994) 445 at 462.

78 Marmor endorses Putnam's recent alternative, derived from Wittgenstein, see Marmor and Putnam ibid.

79 See Jabbari, op cit $\mathrm{n} 13$. 
vocabulary of objectivism whilst accepting the inevitability of regonitiondependency. The alternative which I suggest, tentatively, is the need to drop the vocabulary which informs debates such as these which by its very nature is premised on a Cartesian architecture, and which leads to an impression of active minds confronting an inert world. Once we see the world as being a direct source of motivation to the will, and a source of justification of action, we can move beyond the dualisms of hermeneutics versus structuralism, deconstruction versus sociological theory. Any talk of a Wittgensteinian picture which points to the importance of immersion in a practice as the only way to being able to understand 'truth' in that practice is of course convincing in important respects, but it is misleading if the 'practice' is construed as a pale shadow of something more real external to it. It is, if you like, the order (conflating fact/value, knower/known) of the world which undermines the dualisms of our theoretical architecture in legal theory, something I have tried to capture in my account of the judicial subconscious which conflates reasons and causes. ${ }^{80}$ It is an order beyond the oppositions of Humean and Cartesian thinking which suggests an intuitively appropriate resolution to a dispute. ${ }^{8}$ I regard this modern, particularist, version of natural law as the movement beyond the dead ends of deconstruction (which radically overstates hermeneutic considerations in law) and the sociological theorists who overstate the significance of 'external' structure.

There are great overlaps between the kind of objectivity of particular, albeit transient, contexts which I have defended and the views of Aquinas and Aristotle on a similar point. The difference is that theirs is an objectivity which is linked to human nature and the dipositional properties which ground it and mine is linked to place and context. The difference between radical particularism and generalist or universalist objectivism (as found in Aristotle and Aquinas) is that the circumstances here are not to be seen as repeatable elsewhere. Lisska cites an illuminating passage from Martha Nussbaum concerning what she calls the "non-relative virtues' in Aristotle which illustrates this:

"What I want to stress here is that Aristotelian particularism is fully compatible with Aristotelian objectivity. The fact that a good and virtuous decision is context-sensitive does not imply that it is right only relative to, or inside, a limited context any more than the fact that a good navigational judgement is sensitive to particular weather conditions shows that it is correct only in a local or relational sense. It is right absolutely, objectively, anywhere in the human world, to attend to the particular features of one's context; and the person who so attends and who chooses accordingly is making, according to Aristotle, the humanly correct decision, period. If another situation should ever arise with all the same ethically relevant features, including contextual features, the same decision would again be absolutely right." ${ }^{2}$

What I have tried to suggest is that there can be none of the kind of recurrence suggested in Nussbaum's last sentence. The notion of an order in law is more in the nature of a new lava flow: there is a constant moving on and a constant uniqueness of situation unfolding before the courts. It is

80 See ibid.

81 In this way it may be possible to defend some form of Dworkinian 'right answer' thesis, yet the risk of misunderstanding outweighs the possible advantages.

82 M. Nussbaum, 'Non-Relative Virtues' in M. Nussbaum and A. Sen, The Quality of Life, (Oxford, OUP, 1993) 257, cited in Lisska, op cit $\mathrm{n} 7$ at p 217 
thus that law is bound up with living, active, contexts; that its objectivity is one of ceaseless response to new contexts.

\section{CONCLUSION: THE GOD OF SMALL THINGS}

The God of traditional natural law is a brooding uniformity in the sky, without gender, sexuality, or colour. He is a Man of Principle not of compassion and particularity. While Augustine's God was prepared to get his hands dirty, by striking down inferior human laws, by the time of Aquinas any talk of God had become almost redundant to a conception of natural law, with human law and society left to follow its own logic. In modern times the Kantian God of Finnis is a very remote being who contributes very little to the development of substantive law.

But how far should we leave natural law to the generalists? Can we keep God as a postscript, as a posited essence atop an Aristotelian pyramid of virtues, like a fairy on a Christmas tree? Any natural lawyer worth their salt will want God to shape every detail of law. The issue for all natural lawyers is how to bring the requirements of eternal order into every detail of life. This is not Aquinas's dualistic conception of determination, the implicit assumption of an inert realm where God has no voice, but a seeing of the divine in all contexts, perhaps dimly but always exerting a voice. It is thus that small situations are imbued with meaning, and not through their governance by impersonal precepts and principles. We have to choose: do we want to give expression to the real life of that which is beyond duality, or do we want merely to walk amongst the shadows of mental oppositions?

If we can take our post-modernism into natural law, and see that compassionate sensitivity is the very essence of the order in law, we might be a little less embarrassed to speak the language of natural law. In between physical faculties and abstract mental concepts, there is the inexpressible sense of the demands of context which helps us most of the time. Judges need to find this sense for themselves, and not just emulate those who demonstrated great sensitivity in the past. In law it is important to work out what belongs to secular dust and what expresses true order. The form of particularism I have defended is a position of natural law since it is not concerned with imposing order on case law but rather with responding to the requirements of order. These requirements are not deduced or determined by the use of principles but by a still, silent immersion in context. The atrophy of intuitive ability is currently so severe that most people reading this will have difficulty in seeing the deeper import. But despite this, in the intuitive wisdom of the heart we glimpse what is meant here. We know in our bones when mundanity is in the ascendant, when the still quiet sense has been destroyed by a mechanical language of principle. 